\title{
Research On Interactive Micro-teaching Model Under The Informatization Environment
}

\author{
Weiyan Liang \\ Jiaying University \\ School of Education Science \\ Meizhou, Guangdong,China \\ e-mail:liangweiyan@jyu.edu.cn
}

\begin{abstract}
The impact of information technology on social life is comprehensive, it is micro-teaching model, the development of information technology provides a way to achieve a more diverse and more superior teaching effectiveness for micro teaching, development of web-based information The interaction that is typical advantage is reflected micro teaching mode. This article is based on the interaction of micro-teaching model under the informatization environment studies, micro-teaching model proposed interactive performance reflects, and then from the "teaching" and "learning" the information presented on two levels of micro teaching mode interactive realization.
\end{abstract}

Keywords-information technology; interactive teaching; Micro Teaching; Educational information; model

\section{EDUCATIONAL INFORMATION AND INTERACTIVE TEACHING}

\section{A. Educational information}

Information that is computer-based, modern communication tools and networking platform for the carrier's digital technology development trends, information is one of the main trend of world development, and its efficient integration, collaboration, Unicom function effectively promoted the traditional economy transformation and upgrading of industrial and social activity pattern. Educational activities, too, the education information technology combined with, that is the information included in the field of education, the traditional mode of education to digital, intelligent, network-based, interactive multimedia development, including digital means education system development standardization, integration and stabilization; refers to the teaching of intelligent human behavior, simplification and mechanization; refers Unicom network and share educational resources and information within a broader space to achieve; it is interactive refers to the two-way communication and exchange teaching subject and object, between the subject and tools; multimedia teaching mode refers to virtualization, pluralism and visualization.

Further, the definition of educational information can be interpreted from two levels of broad and narrow, broad education information refers to information throughout the education system, including the concepts of education, educational model, environmental education, educational methods, educational system, educational technology, educational resources, educational organizations and other holistic information technology, engineering education is a systematic modernization; narrow the educational information refers only to modern information technology for education and teaching tool, in order to develop and improve students' information technology capabilities andliteracy, improve teaching quality and effectiveness, to better promote the development of the education system to adapt to modern needs, a development trend of teaching goals. Information technology has been integrated into all aspects of social life and production, and educational information also become an inevitable trend and nature of demand for education.

\section{B. Interactive teaching in informational environment}

Interactive way of teaching compared to traditional teaching model significance has been proved by practice, and has become a major trend in the development of modern teaching mode, and development of information technology, compared with interactive teaching provides more convenience and space. Interactive teaching information technology environment that is taught in schools and teachers will be in the process of teaching resources, teaching methods, teaching content with IT organic, fully integrated, and then complete the teaching mission of teaching methods to achieve educational goals. One big advantage of information technology development that is its efficient interactive collaboration, and information on teaching the same advantages to undertake this typical feature, changing the traditional teaching middle school is always in a rigid position of passive acceptance of the status quo, so that students can be more flexible choose teaching time, place and content, while based interactive information integration is also better address the students and teachers of binary fragmentation problems, which teachers and students build democratic cooperation, coordination, organic new state education mode.

Interactive teaching information technology environment based on the following factors need to achieve: First, information-based learning environment, integration of information technology tools and methods in teaching and take advantage of, such as building a network teaching platform; Second, teachers need to have information 
interactive teaching ability and awareness, a good education model is ultimately a teacher to lead and achieve, the ability of teachers and consciousness determines the interactive teaching and performance targets under the information environment to achieve; Third, should adhere to a comprehensive development of students teaching objectives, in essence teaching model, its still is a tool for "all-round development of students," the essence of the educational function of the service, so that interactive teaching Information Environment must focus on "student development" core essence commenced practice.

\section{INTERACTION OF MICRO-TEACHING MODEL UNDER THE INFORMATIZATION ENVIRONMENT ANALYSIS}

\section{A. Micro-teaching model}

Micro-teaching mode refers to the modern teaching model under development and educational needs of diverse backgrounds, teachers using a variety of methods of teaching methods of knowledge around a particular point or a certain teaching and start teaching activities. Nanjing Normal University Professor Zhang Yichun micro lesson was evaluated characteristics: First, do not humble bit micro: micro lesson though short, but education distinctive, occupy an important position in the modern education system; Second, no small micro lesson: Although micro lesson short, but the effect is obvious education, content-rich, are often able to dig all the connotations of a knowledge points and links; Third, do not micro-step slow: micro lesson although only around a single point of knowledge or link an issue, but it was not significant Slow, steady progress in its emphasis, one by one break point teaching problem; Fourth, the effect is not thin micro: micro lesson a little, step by step to expand knowledge, step by step, add up, eventually paid off, reach teaching goals.

Micro-learning courses for teachers of a "course" is a tool in order to grow, but also a teacher spontaneous "grassroots" way of teaching and research, because it is the provider of micro-curriculum classroom teachers themselves, there is not much highly theoretical, not rely on "experts", each learning masters, are available through a simple training course and into micro developers to make their work to provide peer learning and inspiration. Here, everyone is both a learner, but also developers, creators, "research partners" between the formation of a learning community. In this sense, the course is a new micro, touted by the majority of teachers, teachers explored the growth of a new paradigm.

Micro-teaching model is relying on micro courseware to achieve, micro courseware that is focused on a relatively short period of time, tiny detail about the content, compared to the ordinary teaching mode courseware, micro courseware flexible, free, and easy disposal, without time and space constraints and other advantages, especially with the development of modern information network technology and multimedia technology, micro courseware more presents many new features and typical advantages, such as mobile, interactive, and so ubiquitous, both in the classroom lectures taught as a subject, can be used as teaching aid and extend content to play a role in a flexible and efficient after-school and other times.

\section{B. The necessity of interactive micro-teaching model under the informatization environment}

The above analysis shows that the micro-teaching model has practical needs of information technology, and information technology for the effectiveness of microteaching model implementation provides greater possibility for the modern development of micro-lesson provides more space. Micro-teaching model with a combination of information is both inevitable demand and micro-teaching functions to achieve their own development, as well as information on its interactive capabilities to achieve the integration of collaborative approach, micro-teaching model whereby information technology environment will This has the significant advantage of interactivity. Under the current needs of education and teaching background, interactive micro teaching mode information environment necessity of its development, mainly as follows: First, students interested in strengthening teaching. Teaching Practice already showed interest is the best teacher, self-interest-based learning tend to have more favorable results than the passive filling teaching learning. Information Environment interactive teaching model is focused on the decline reflects the "interest" of the advantageous features, the use of lean and lively text, images, sound, and even animation, video, interactive games and other information media courseware authoring tools micro and carry out teaching activities, students can choose, while timely interaction with teachers based on network connectivity, namely mesh, threedimensional, two-way teaching revolutionized the shortcomings of the traditional linear, flat, one-way teaching mode, the students have a great attractive, and thus stimulate students' interest and desire to improve learning efficiency; Second, cultivate awareness of innovation and collaboration of teachers and students. The needs of modern society for talent already not "ears do not hear out of the window, one read only the books of sages" scholar-type talent, but allround development, with social viability of the integrated personnel, including innovation, cooperation and awareness that is high Typical performance characteristics of quality talent. Micro-teaching model information not only fully grown in micro courseware design, development and use and exercise the teachers and students awareness of innovation, based on both its interactivity, connectivity and interoperability also strengthened the students and teachers, students and themulti-directional links between communication, social skills and cultivate a sense of cooperation of students; Third, students of information technology and modern consciousness. Information technology is one of the main elements of modern, but also where the trend of social development in the 21 st century is the information age, the Internet age, and the overall development of the school as a training organization personnel, personnel training its fit with the needs of society is necessary to focus on the subject . And traditional closed, rigid campus teaching different interactive teaching mode declining Information Environment precisely meet the 
requirements of this reality, the information often use micro class computer networks, mobile phones and other mobile terminals to share courseware publishing, interactive and easy to implement two-way communication effectiveness, including network technologies and practices related to information technology awareness, modern consciousness is another harvest students receiving micro teaching contents outside.

\section{THE DESIGN OF THE INTERACTIVE TEACHING MODEL OF MICRO-TEACHING IN INFORMATIONAL ENVIRONMENT}

Micro Teaching in the Information Environment carried out, based on micro courseware content, teaching methods will be an information technology and micro-learning combines its usual practice to performance and to strict style and wide-type modes: strict formula interactive micro lesson includes a typical case, assigning tasks, quizzes training, wide decline lesson is more freedom and flexibility, you can use the network terminal publish shared micro courses to enable students to choose, consciously or unconsciously learning where knowledge points. As mentioned above, interactive information environment under micro teaching model has other great advantages incomparable teaching methods, so its teaching should be designed to ensure the completion of the course content, teaching objectives to achieve under the premise, to maximize its interaction reflects in order to maximize the effectiveness of the practice of micro-class education information technology environment, and to achieve this goal should first interactive design based on micro-teaching, in order to highlight the micro-lesson interactive features.

\section{A. micro-lesson interactive achieve carrier selection.}

Information Environment micro lesson achieve a variety of carriers, and if focusing on the micro-lesson interactive achieve, you should first based on the diversity of modern communications technology and social networking tools and the choice of more interactive support tools, such as web pages, phone information, QQ and other instant messaging tools, such as micro-channel social networking tools. Phone information can be used to convey a simple test, teaching reminded learn vocabulary and grammar, poetry and classical statement Brief etc; page capacity is relatively larger, richer contents can carry with animation, video and other forms of knowledge do more detailed and profound teaching; QQ, micro-channel, microblogging, instant and strong tool that can carry a high number of timeliness, need real-time interactive microlesson content. In the tool selection process, requires teachers with modern consciousness, master of modern social networking tools to achieve an efficient microteaching model micro lesson by a reasonable choice tool carrier, timely interaction.

\section{B. micro-lesson interactive content to achieve.}

Micro interactive teaching mode of information environment should be fully reflected in the courseware content, in courseware design should be more open sexual content organization and design courseware content, while membership in order to attract students attention, mobilize students interest, it can also be left to the student to play and imagination, and further between teachers and students, life and interaction between the reserved space. For example, after the micro teaching English listening, the teacher to make a video sharing Listening micro courseware to students, teaching does not mean the end, but should be based on the needs of interactive further proposed openended questions: Please talk to your watch English Video feelings too? Proposed open-ended questions like this that greatly strengthened the interaction of micro lesson, but to deepen the teaching effect. Micro-class teachers should be good at creating content design scene, good at raising guide and divergent issues, and actively guide students to express and exchange views, and to learn the student learning process and give feedback timely and necessary response.

\section{C. the use of micro-lesson interactive technology implementation.}

Micro-class interactive technology used mainly in the "man-machine interaction," that guide the interaction between man and machine through the rational use interface, and thus exercise the students' ability to operate independently and information awareness. Interface design is necessary to meet the needs of user-friendly design, and strive to simple, smooth, and not for the realization of human-computer interaction force between the manmachine interface with micro lesson content, micro-microteaching lesson carrier interrupted process, to ensure that the harmonious, consistent, as you can take advantage of visualization, password issues, divergent thinking test, clearance and other human-computer interaction model to help students convert ideas to expand the space of thinking. In addition, human-computer interaction can also be more attractive "micro class game" mode can be achieved. Micro entertaining game is a lesson in the way the game contents professor taught methods, micro-class games on the computer and information technology are higher, while the micro-details of lesson content and teaching requirements are also higher, requires teachers to professional competence to deal with.

\section{THE POLICY OF INTERACTIVE STUDY OF MICRO- TEACHING MODEL UNDER THE INFORMATIZATION ENVIRONMENT}

Interaction is a mutual process, interactive microteaching model information environment while emphasizing teacher interaction in micro teaching ability to achieve, should also look into the same student interactive microlesson learning to . For the students, how to fully grasp the information to identify and micro-teaching and interactive features to maximize utilization, thereby achieving a multiplier effect for their own learning process, but also related to the research must be covered and solve problems. Because this study, students should be based on interactive learning strategies will decline this lesson of modern teaching mode to maximize the effectiveness of play. 


\section{A. strengthen the ability of micro-lesson learning, positive feedback learning information.}

Students in learning through a modern network of social media micro courses, access to information and its processing capacity is particularly important. Innumerable micro class network resources, faced with a variety of outside interference information, students must strengthen self-learning awareness, strengthen information acquisition and processing capabilities, network ocean, from information technology to capture the beneficial microcourse knowledge, and take advantage of interactive media the first time feedback learning experience, reflect the problems encountered in the study, enhance communication, strengthen awareness and further put forward their views and suggestions on the micro curriculum design, teaching processes and teaching effectiveness, in order kinds of twoway interaction and improve the quality and effectiveness of the micro-teaching, and ultimately improve the effectiveness of micro-teaching.

\section{B. choose to study science model to improve the efficiency of the micro-lesson learning.}

Micro-class is a more flexible and autonomous teaching mode, the traditional teaching model reflects the relevance and systems, while micro-lesson on the contrary, more reflect the independence of the debris in order to enhance their ability to communicate and use value. On the student perspective is concerned, you can take advantage of this feature micro lesson, choose a more flexible, more appropriate mode of learning, such as learning, collaborative learning, closed learning, open learning, online learning, mobile learning and so on. The need for independent thinking knowledge, should strengthen awareness of autonomous learning, solve problems independently, and for collaborative knowledge should actively interact with others, exercise interpersonal skills, expand thinking space, so as to realize the comprehensive development of the individual.
The impact of information technology on social life is comprehensive, it is micro-teaching model, the development of information technology provides a way to achieve a more diverse and more superior teaching effectiveness, schools and teachers should actively seize micro teaching this opportunity to organize educational resources initiative to deal with the multi-exploration, students should also strengthen the ability to actively grasp this new learning tool, teaching mutual practice, bold and innovative, active collaboration, development of information technology and micro-teaching a combination of interactive teaching innovation.

\section{REFERENCES}

[1] Guan Zhongke. Micro courses . China Information Technology Education.2011(17)

[2] Liang Leming. Course Design of Micro Mode - Based on comparative analysis of domestic and micro courses. Open Education Research.2013(01)

[3] Jiao Jjianli. Its application and impact of micro-lesson Primary and secondary IT education.2013(04)

[4] Yang Yanyan. Based on a critical view of classroom interaction. Global Education.2009(04)

[5] Zhang Wenbin. Interactive Teaching of University Teachers "catalyst" role . Heilongjiang Ecological Engineering Vocational College.2011(03)

[6] Jiao Jianli, from open educational resources to "Mu class" - we can learn something, primary and secondary IT education, in October 2012.

Progress

[7] Jiao Jianli, mobile learning applications and research, China Education Network, June 2013.

[8] Jiao Jianli, open China video open class of five keys, China Education Network, January 2012.

[9] Chi Wing Chung, Pan Wentao, "Modern Educational Technology", Higher Education Press, August 2012.

[10] Chi Wing Chung, personalized learning model construction and application environment based on Web2.0, China Educational Technology, August 2012. 